Supporting Information (SI)

\title{
Illuminating Excited-State Intramolecular Proton Transfer of A Fungi-Derived Red Pigment for Sustainable Functional Materials
}

Taylor D. Krueger, ${ }^{\mathrm{a},}$ Janak Solaris, ${ }^{\mathrm{a}, \mathrm{S}}$ Longteng Tang, ${ }^{\mathrm{a}}$ Liangdong Zhu, ${ }^{\mathrm{a}}$ Carter Webber, ${ }^{\mathrm{b}}$ Ray C. Van Court, ${ }^{\mathrm{c}}$ Seri C. Robinson, ${ }^{\mathrm{c}}$ Oksana Ostroverkhova, ${ }^{\mathrm{b}}$ and Chong Fang, ${ }^{* \mathrm{a}}$

${ }^{a}$ Department of Chemistry, Oregon State University, 153 Gilbert Hall, Corvallis, Oregon 97331, United States

${ }^{\mathrm{b}}$ Department of Physics, Oregon State University, 301 Weniger Hall, Corvallis, Oregon 97331, United States

${ }^{c}$ Department of Wood Science and Engineering, Oregon State University, 119 Richardson Hall, Corvallis, Oregon 97331, United States

$\S$ These authors (T.D.K. and J.S.) contributed equally to this work.

* Corresponding Author: Chong.Fang@oregonstate.edu 
$\begin{array}{lr}\text { SI Figures } & \text { S3-17 }\end{array}$

Figure S1. Steady-state spectra of Draconin Red in DMSO S3-4

Figure S2. Resonance structures of the two tautomers of Draconin Red S5-6

Figure S3. Electronic absorption and emission (vibronic) spectra from Franck-Condon $\begin{array}{ll}\text { Herzberg-Teller calculations } & \text { S7-8 }\end{array}$

Figure S4. Fluorescence quantum yield of Draconin Red in ethanol S9

Figure S5. Magic-angle fs-TA spectra \& global analysis of Draconin Red in DCM S10-12

Figure S6. Far-red stimulated emission (SE) peak intensity dynamics from fs-TA spectra of Draconin Red in DCM and DMSO S13-15

Figure S7. Photobleaching data of Draconin Red in DCM and deionized water $\quad$ S16

Figure S8. Photoluminescence lifetimes of Draconin Red in DCM and crystals $\quad$ S17 Additional discussions follow each figure.

SI References (with full authorship of Gaussian 09 and 16 software) 


\section{$\underline{\text { SI Figures }}$}

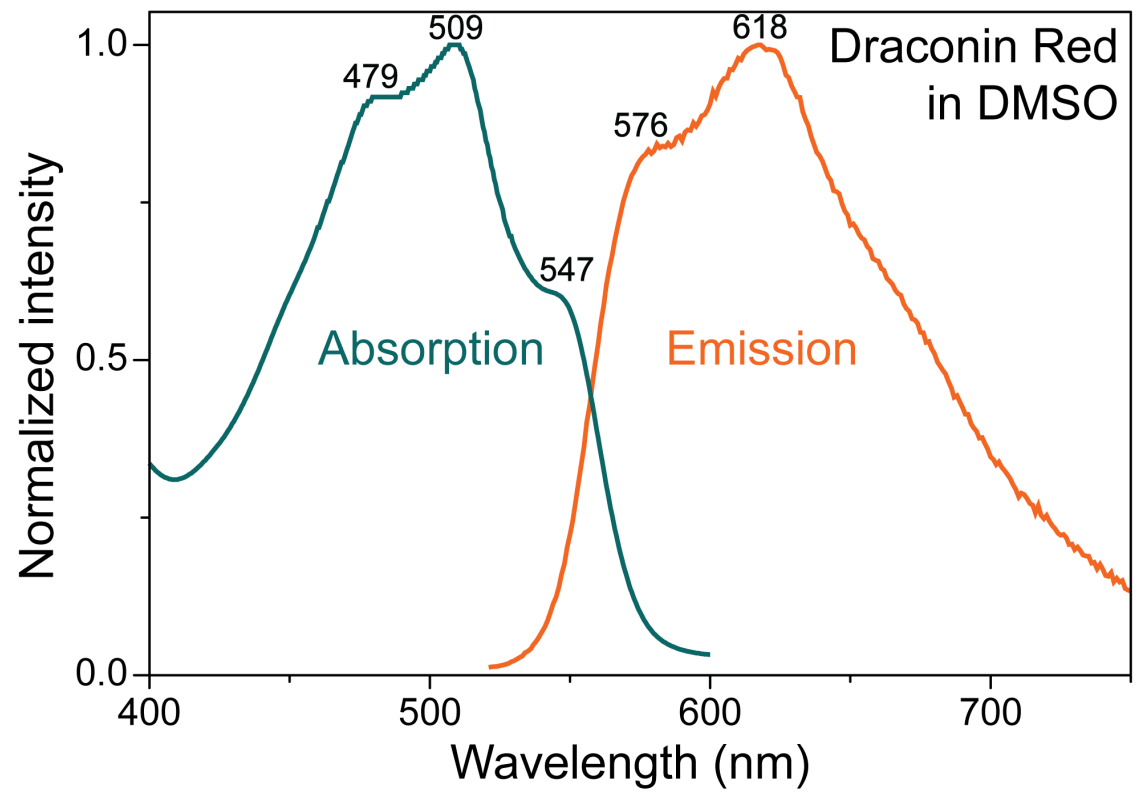

Figure S1. Steady-state electronic spectra of Draconin Red in DMSO. Peak positions (in nm unit) of both absorption (cyan) and emission (orange) spectra are denoted. The fluorescence emission spectrum was obtained with $500 \mathrm{~nm}$ excitation.

Notably, the absorption and emission spectra of Draconin Red in DMSO (above) are similar to that in DCM (Figure 1 in main text), though the vibronic coupling is less resolved in both electronic spectra potentially due to inhomogeneous broadening in the more polar solvent like DMSO. ${ }^{1,2}$ The absorption profile is blue-shifted by $\sim 2 \mathrm{~nm}$ in DMSO (vs. in DCM), suggesting that the ground state of Draconin Red is slightly better stabilized due to the H-bond-accepting strength of the solvent. By fitting the absorption spectrum in DMSO (cyan trace in Figure S1), it was determined that DMSO slightly favors PS over PA more than that in DCM. Moreover, the blue shoulder (at $\sim 576 \mathrm{~nm}$ ) in the emission spectrum is more intense in DMSO (orange trace, Figure S1) compared to its counterpart in DCM (red trace, Figure 1c). This comparison indicates that the 
PS* form is more populated following photoexcitation, corroborated by the less pronounced vibronic shoulder above $650 \mathrm{~nm}$ mainly due to PA* (the redder-emitting species) in DMSO.

Overall, with a slightly larger PS population, these results indicate that DMSO may inhibit a full transfer of the proton originating from PS*. Upon comparing the emission $\lambda_{\max }$ in DMSO vs. DCM, the peak is red-shifted by $\sim 10 \mathrm{~nm}$ in the former solvent. This finding complements the fsTA data, where an additional redshift of the redder SE feature occurs with an 7-12 ps time constant (see red $\rightarrow$ blue traces and the associated tilted gray arrows in Figure $4 \mathrm{~b}, \mathrm{~d}$ ) attributed to the solvation-aided relaxation, whereas such an extra redshift was not observed in DCM on similar timescales (see red $\rightarrow$ blue traces and the associated vertical gray lines in Figure $4 a, c) .{ }^{3,4}$ It is thus plausible that the more polar DMSO with stronger H-bond accepting capabilities (than DCM) better stabilizes the excited state of Draconin Red. This experiment also provides a useful strategy to grow crystals of Draconin Red in different solvents (e.g., acetone) to modify and control the output emission/optoelectronic properties (see Section 3.7 in main text for details). ${ }^{5}$ 


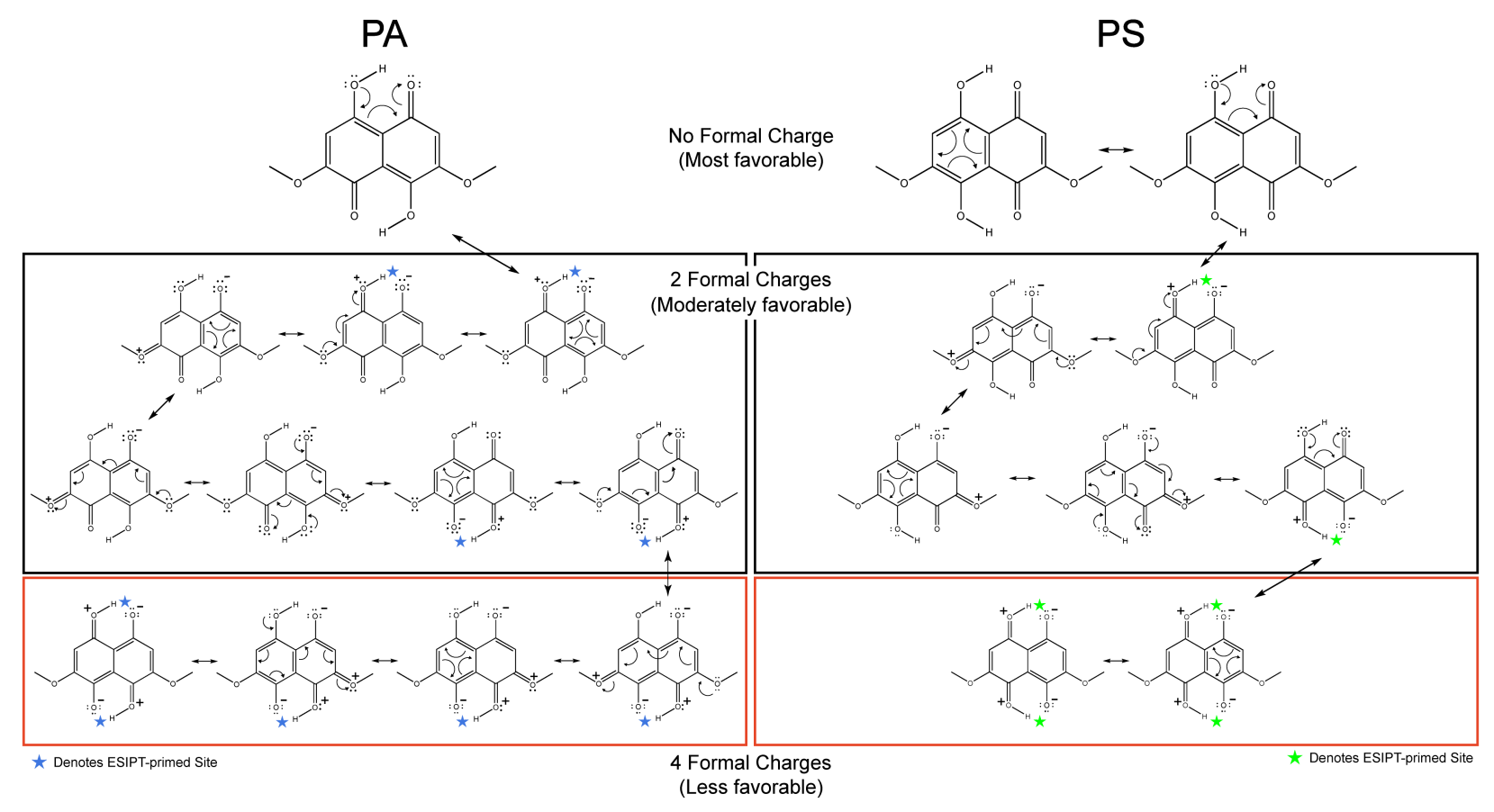

Figure S2. Possible resonance structures for each tautomer of Draconin Red. For PA tautomer (left panels), it possesses more resonance structures with excited-state intramolecular proton transfer (ESIPT)-primed sites (denoted by blue stars) than those for PS tautomer (right panels) with ESIPT-primed sites (denoted by green stars). The relationship between total number of formal charges and the chromophore tautomer stability is listed in the middle.

Notably, the resonance structures of the two tautomers of Draconin Red provide some useful fundamental insights into the stability and photoresponse of each tautomer. Highly unfavorable structures such as those involving the formation of carbocations were omitted from consideration since their contribution to charge distribution and behavior can be assumed to be negligible. The PS tautomer is shown to have two configurations (see top right panels in Figure S2) available to it that do not require electron displacement to or from an oxygen, which may be why it is the more energetically favored tautomer. Interestingly, tautomer PA has many more structures than PS 
involving the separation of charges, including many where a negatively-charged oxygen is optimally poised for a nucleophilic attack on a neighboring hydrogen attached to a positivelycharged oxygen (see the stars denoting ESIPT-primed structures in Figure S2, nine blue stars for tautomer PA vs. six green stars for tautomer PS). 

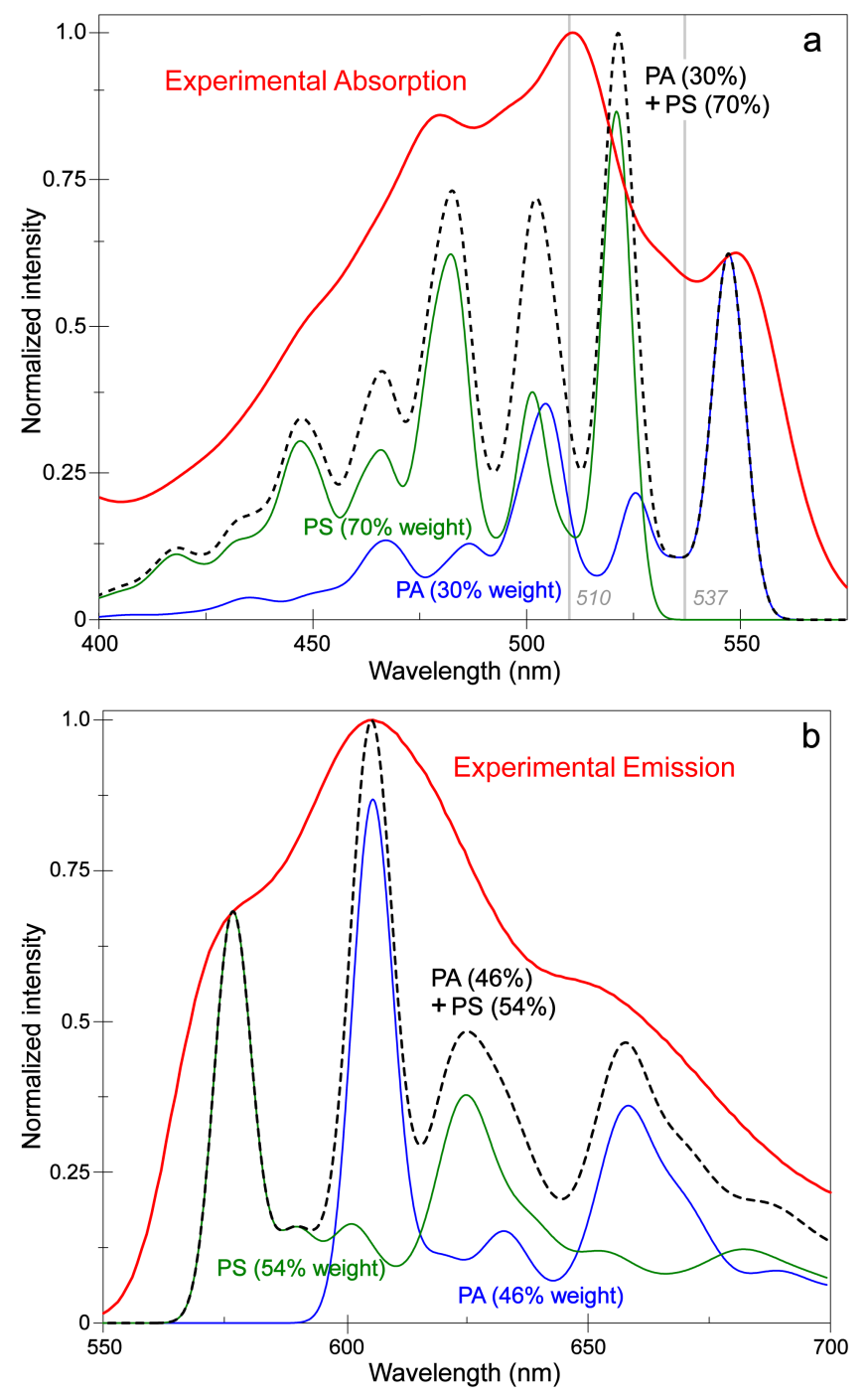

Figure S3. Comparison between experimental and calculated vibronic spectra of Draconin Red in DCM. Steady-state electronic (a) absorption (red) and (b) emission (red) spectra are overlaid with the calculated Franck-Condon/Herzberg-Teller one-photon absorption (PA, blue; PS, green; panel a) and emission (PA, blue; PS, green; panel b) spectra, summed and weighted (ratios listed in the insets) for optimal agreement in relative peak intensity (black dashed curve) with the experimental spectrum (red solid curve). Excitation wavelengths for fs-TA are shown in panel a.

Notably in contrast to Figure $1 \mathrm{~b}, \mathrm{c}$ (main text), the narrower $\left(270 \mathrm{~cm}^{-1} \mathrm{FWHM}\right)$ band intensity parameters here show a more dominant PS population in $\mathrm{S}_{0}$ (i.e., $70 \%$ in Figure $\mathrm{S} 3 \mathrm{a}$ ) and a 
pronounced population shift toward the PA tautomer from the absorbing to emitting population (i.e., $30 \% \rightarrow 46 \%$ of PA). This result suggests that broadening effects caused by potential coupling of the two tautomeric chromophores may convolute the overall observed spectrum of Draconin Red in solution, masking somewhat the intrinsic magnitude of the tautomeric population disparity. ${ }^{6,7}$ 


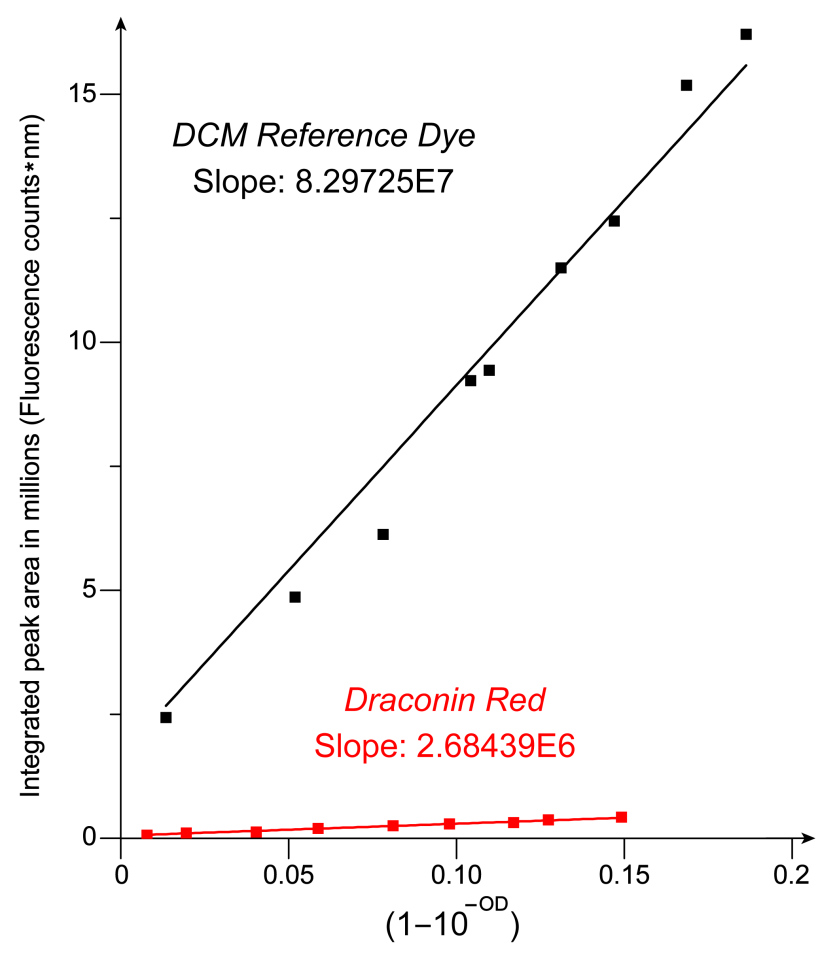

Figure S4. Determination of fluorescence quantum yield (FQY) of Draconin Red using the reference dye DCM in ethanol. Least-squares linear fits (color-coded solid lines) for the integrated emission peak areas are plotted against the percentage of the absorbed photons for Draconin Red (red squares) and DCM dye (black squares) with the slope values listed.

Using the retrieved slope values above ${ }^{8}$ and Equation (1) in main text, the FQY of Draconin Red in ethanol was determined to be $\sim 1.41 \%$, which is more than one order of magnitude higher than another spalting wood fungus-derived pigment, xylindein, in DCM (see main text). ${ }^{9,10}$ The FQYs of Draconin Red in other solvents (DMSO and DCM) were retrieved the same way, using a bluer integration range of 560-650 $\mathrm{nm}$ for the fluorescence emission band (vs. $600-700 \mathrm{~nm}$ for data plots in ethanol as shown in Figure S4). Upon $500 \mathrm{~nm}$ excitation, the measured FQYs $(1.41 \%<1.67 \%<3.66 \%)$ seem to correlate negatively with the H-bond donating/accepting strengths of solvents $(\mathrm{EtOH}>\mathrm{DMSO}>\mathrm{DCM})$, which corroborate fs-TA results that the apparent fluorescence lifetime is longer in DCM (Figure 3) while stronger H-bonding quenches fluorescence (main text). 

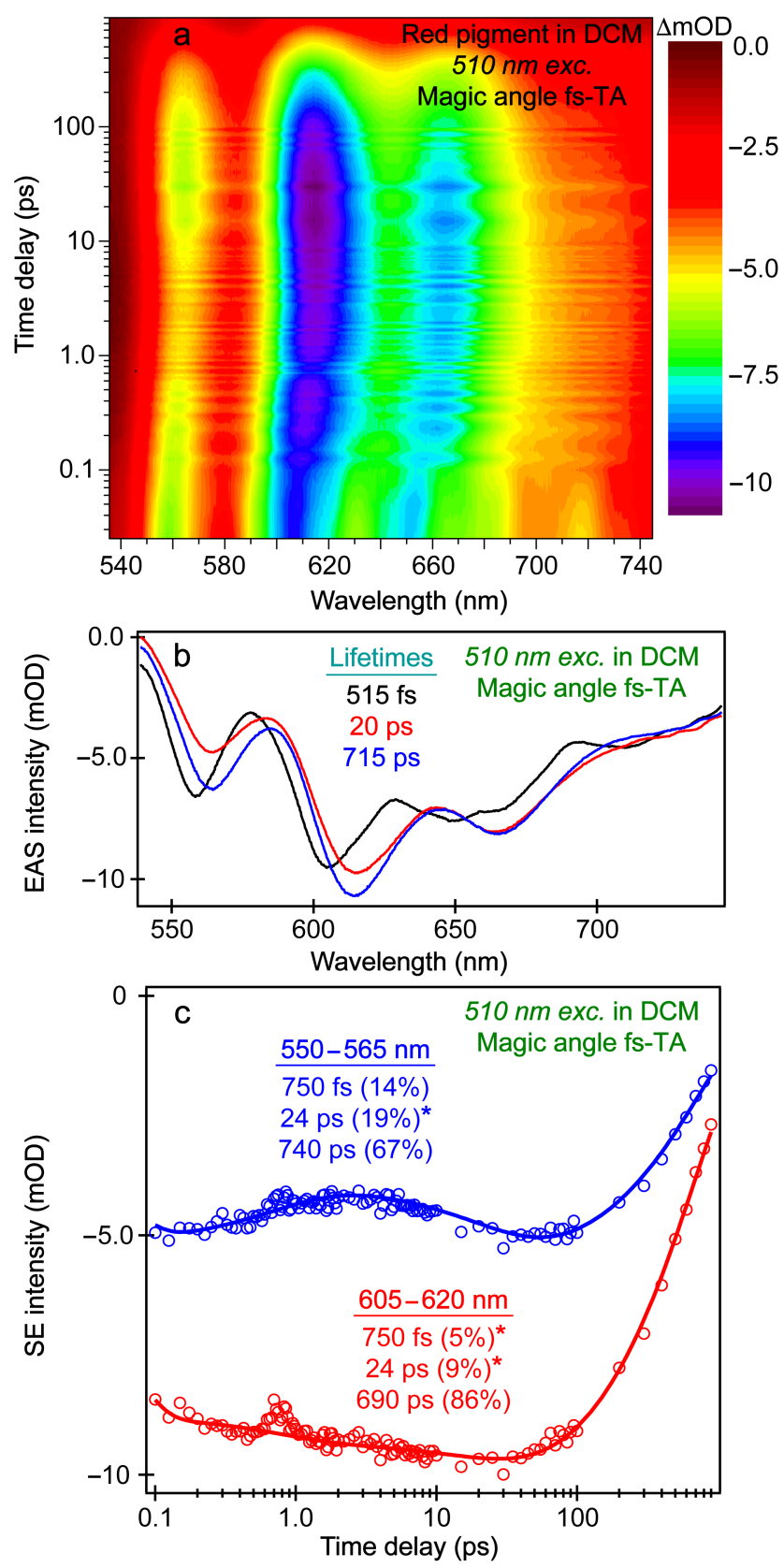

Figure S5. Time-resolved magic-angle fs-TA spectra of Draconin Red in DCM. (a) Semilogarithmic 2D-contour plot of the fs-TA spectra of Draconin Red in DCM after $510 \mathrm{~nm}$ excitation with a probe region from $\sim 540-740 \mathrm{~nm}$. The intensity colorbars in milli-OD (optical density) units are shown on the right side. (b) Global analysis of the Draconin Red fs-TA spectra represented by the sequential evolution-associated spectra (EAS) with color-coded lifetimes (black $\rightarrow$ red $\rightarrow$ blue) listed in the inset. (c) The SE peak intensity dynamics of the blue SE (550- 
$565 \mathrm{~nm})$ and red SE $(605-620 \mathrm{~nm})$ for the magic-angle TA experiment in DCM. The multiexponential least-squares fits (color-coded solid curves) are overlaid with spectral data points (open circles). The retrieved time constants are listed in the inset with the respective amplitude weights given as percentages. The asterisks indicate the rise time constants.

To confirm the assignment of molecular rotational relaxation to the 24-27 ps time constant observed during fs-TA experiments on Draconin Red in DCM (main text Figures 2-4), the magicangle fs-TA experiments ${ }^{11}$ were performed upon $510 \mathrm{~nm}$ excitation in DCM to remove the contribution of rotational motion from the observed intensity dynamics. As shown in the contour plot of fs-TA spectra (Figure S5a), transient spectral profiles during the magic-angle experiments remain similar to the "normal" parallel polarization with prominent SE features at $\sim 560$ and 610 $\mathrm{nm}$. The frequency shifts of primary SE bands are also similar to those presented in Figure 2a (main text), while the bluer and redder SE features display a $\sim 6 \mathrm{~nm}(558 \rightarrow 564 \mathrm{~nm}$, hence an energy gap of $\left.\sim 190 \mathrm{~cm}^{-1}\right)$ and $11 \mathrm{~nm}\left(605 \rightarrow 616 \mathrm{~nm}\right.$, hence an energy gap of $\left.\sim 290 \mathrm{~cm}^{-1}\right)$ redshift with a 515 fs lifetime (black to red traces, Figure S5b). The redshift of the bluer SE peak could be the PS population that cannot overcome the ESIPT barrier (see main text), while the redshift of the redder SE peak represents the transiently formed ESIPT photoproduct (PA*') population that lies lower than the unrelaxed excited state population (PA*, see Figure 7). Similar to the parallel polarization fs-TA spectra (Figure 4a in main text), there is a lack of wavelength shift for the EAS traces (particularly the SE peaks) on longer timescales (red to blue traces, Figure S5b).

While the magic-angle TA experiments lend confidence to the rotational relaxation assignment by the clear lack of a prominent intensity decay on the 24-27 ps timescale (corroborated by another magic-angle TA experiment using $537 \mathrm{~nm}$ excitation), a rather interesting result was obtained: instead of an intensity decay, the SE intensity rises on a similar timescale. Though beyond the 
research scope of our current work, this result could be further investigated by comparing the fsTA spectra of Draconin Red in various solvents (beyond the currently used DCM solvent) during magic-angle, parallel, and perpendicular polarizations between the pump and probe pulses. The current finding can be tentative evidence that a portion of the chromophore population that undergoes rotational relaxation does not return to ground state, yet becomes further stabilized with an increased oscillator strength reminiscent of the rotational barrier observed for another organic chromophore, 8-methoxypyrene-1,3,6-trisulfonate (MPTS), in solution. ${ }^{8}$ Moreover, the precision in determining the exact magic angle condition using a specific polarizer and waveplate combination in our setup (see Section 2.4) may introduce slight discrepancies. We note that the sub-ps component ( $\sim 750 \mathrm{fs})$ and longer time constant (690-740 ps) are not altered significantly upon comparing the normal (Figure 3a) and magic-angle (Figure S5c) conditions, confirming that these temporal components are not directly related to molecular rotational relaxation. ${ }^{4,11}$ In particular, the decay of $\sim 555 \mathrm{~nm}$ SE band on ultrafast timescale occurs with approximately half of the amplitude weight compared to the similar condition shown in Figure 3a (e.g. 14\% vs. 30\%), though this parameter could be influenced by the $\sim 24$ ps rise component (Figure S5c). 

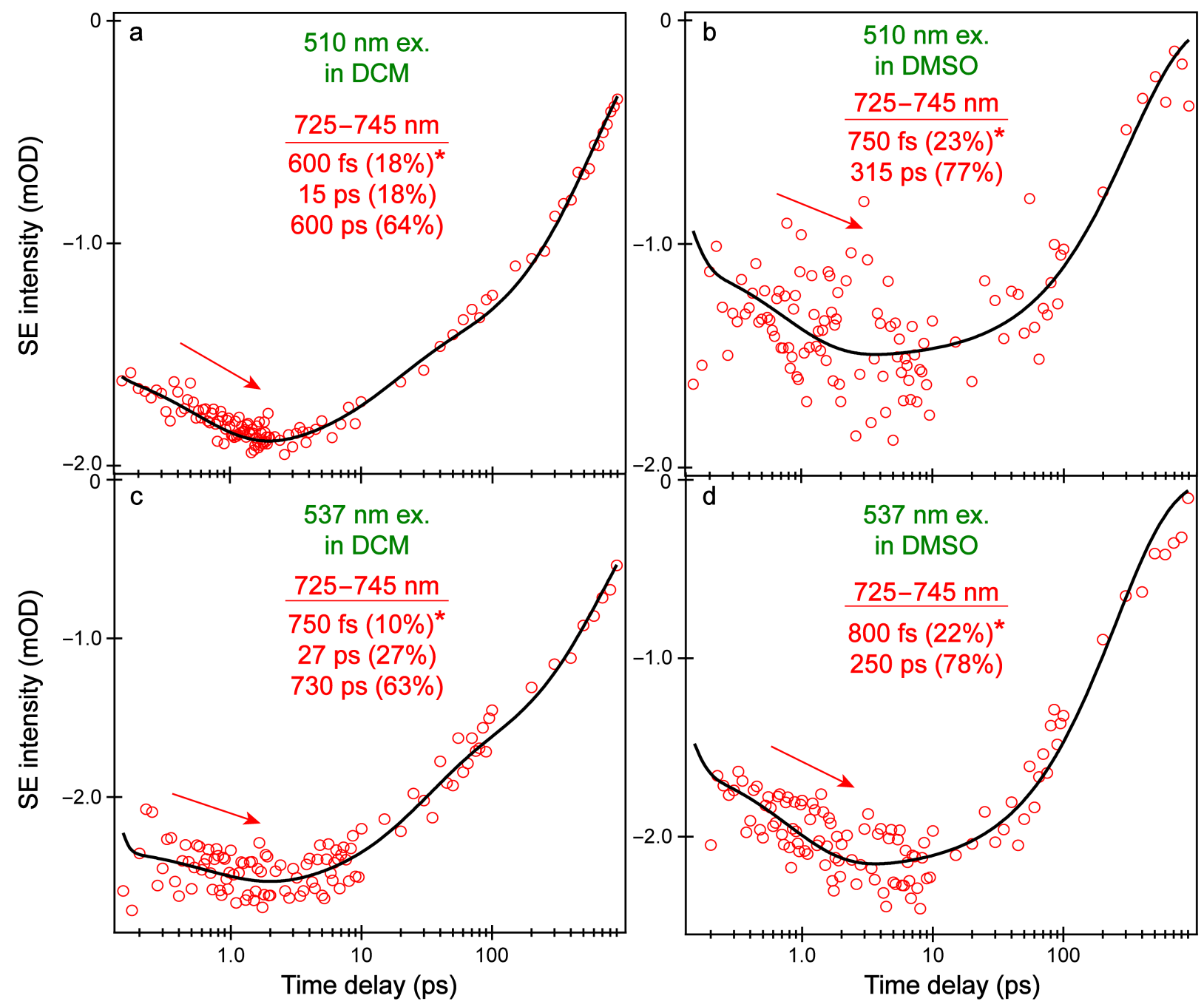

Figure S6. Far-red SE band dynamics. Integrated intensities of SE (725-745 nm) with 510, 537 $\mathrm{nm}$ excitation in DCM/DMSO are shown in $(\mathrm{a}) /(\mathrm{b})$ and $(\mathrm{c}) /(\mathrm{d})$, respectively. The multiexponential least-squares fits are shown as black curves (solid) overlaid with data points (red open circles). The retrieved time constants and amplitude weights are listed in the insets. The asterisks indicate the time constants associated with rise components, highlighted by red arrows by the data points.

The prominent rise of the far-red SE band provides several additional insights into the photoresponse of Draconin Red in solution. This broad and weak SE feature can be attributed to transient formation of a transition state wherein the proton is shared between the adjacent carbonyl 
groups of Draconin Red (see Figures 1a and 5 in main text for chemical structures of PS and PA tautomers), on the basis of quantum calculations of the transition state structure which is predicted to absorb and emit the reddest wavelengths amongst the pertinent tautomers (see Section 2.5 for relevant methods). There are several trends that are consistent with the fs-TA data presented in main text with bluer probe regions (see Figures 2-4). First, the rise of far-red SE feature occurs with a similar time constant as initial decay of the $\sim 555 \mathrm{~nm}$ SE feature (Figure 3). Second, the rise (decay) of far-red SE feature (555 nm SE feature) is more prominent following $510 \mathrm{~nm}$ excitation than $537 \mathrm{~nm}$ excitation. Third, the rise (decay) of far-red SE feature (555 nm SE feature) is more prominent in DMSO than that in DCM (e.g., $23 \%>18 \%$ after $510 \mathrm{~nm}$ excitation and $22 \%>10 \%$ after $537 \mathrm{~nm}$ excitation in Figure S6). All these comparisons substantiate the sub-ps process as being intimately related to the initial ESIPT reaction of $\mathrm{PS}^{*} \rightarrow \mathrm{PA}^{*}$ ' (see Figure 7 for illustration of the reaction path).

The other time constants representing the rotational relaxation and apparent fluorescence lifetime largely match between the $\sim 555 \mathrm{~nm}, 610 \mathrm{~nm}$ (Figure 3), and far-red SE features (Figure S6). While the far-red SE rise time constant matches the $\sim 555 \mathrm{~nm}$ SE decay time constant, an unexpected result manifests when comparing the rise of $\sim 610 \mathrm{~nm}$ and far-red SE features. Notably, the $610 \mathrm{~nm}$ SE band displays a weak rise component with a $400 \mathrm{fs}$ time constant attributed to the PS*' $\rightarrow$ PA* $^{*}$ tautomerization beyond the instrument cross-correlation time (Figure 3a,c). However, the far-red SE band rises with a slightly longer $600-750$ fs time constant representing the formation of a transition state in DCM (Figure S6a,c). Typically, the formation of a transition state would occur faster than the formation of ESIPT photoproduct, PA*', yet the opposite result was observed. This result may stem from the intrinsic inhomogeneity ${ }^{12,13}$ of Draconin Red groundstate population in solution, and upon photoexcitation, a small portion of the PS population can 
undergo a rapid ESIPT reaction to form PA tautomer in $\mathrm{S}_{1}$ (e.g., $\sim 400$ fs), while another PS population undergoes a relatively slower $(>750 \mathrm{fs})$ proton transfer. This interpretation would suggest that the $\sim 750$ fs rise/decay of the far-red/555 $\mathrm{nm}$ SE features represents an average timescale for ESIPT process. Furthermore, the intrinsically faster $\mathrm{PA}^{*} \rightarrow \mathrm{PS}^{*}$, transition than $\mathrm{PS}^{*}, \rightarrow \mathrm{PA}^{*}$ ' transition (see Figure 7 in main text) may lead to an apparent lengthening of the intermediate species due to an overall "bottleneck" process of PS*' $\rightarrow$ PA*' ESIPT reaction (with its associated SE band transition oscillator strength), as well as manifestation of far-red SE band accumulation on the $600-750$ fs timescale before the pronounced decay on longer timescales (Figure S6). 


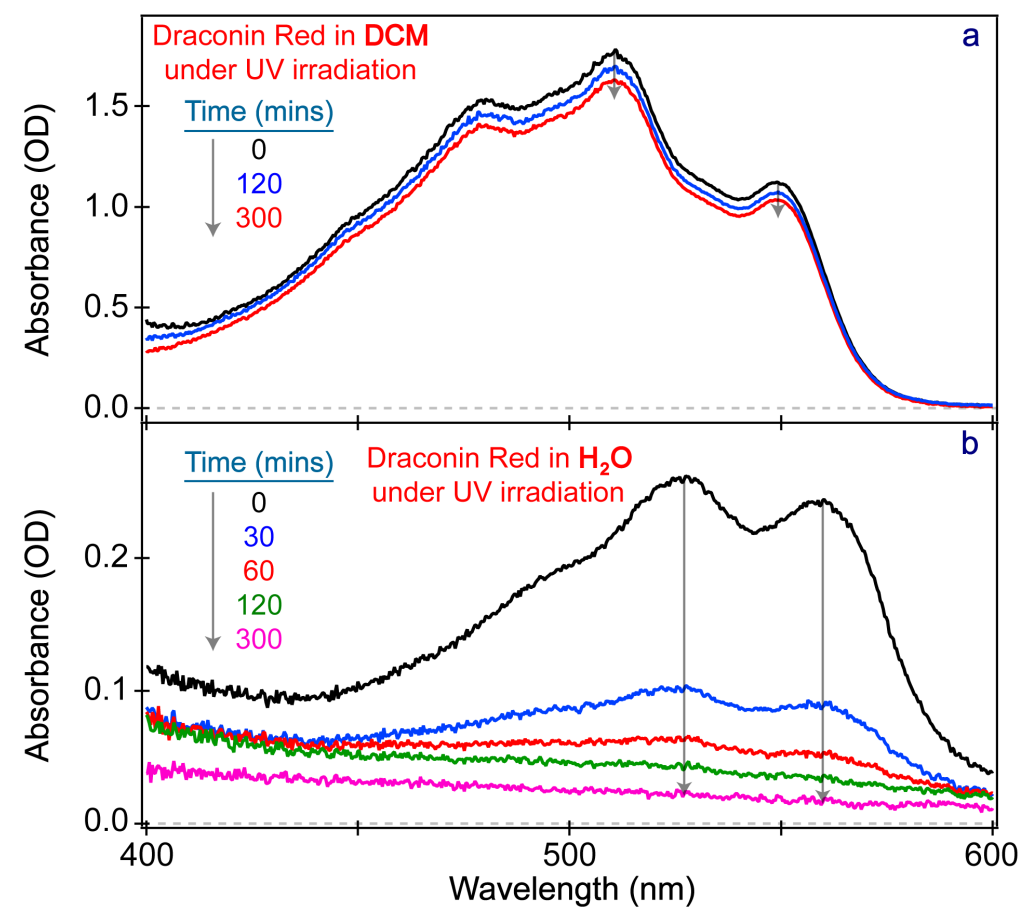

Figure S7. Time-resolved electronic absorption measurements of Draconin Red in (a) DCM and (b) deionized water under ultraviolet (UV) lamp irradiation. Steady-state UV/visible absorbance was taken at 30 minute intervals. The downward arrows (gray) highlight the absorption intensity decrease over five hours of illumination.

Photobleaching data were obtained through measurements of a series of steady-state electronic absorption spectra. An initial absorption spectrum was taken for a fresh sample before being irradiated. The sample was then placed in front of the light source and taken out every 30 minutes for absorbance measurements. Representative spectra were plotted above for the demonstration of a dramatic decrease of Draconin Red's photostability in water (Figure S7b, $\sim 50 \%$ absorption intensity drop within the first 30 minutes) than that in DCM (Figure S7a), likely due to the deprotonation events of Draconin Red in water with the visibly red-shifted absorption peaks from those in DCM. ${ }^{9,10}$ The H-bonding and ESIPT could help to maintain the chromophore stability. ${ }^{9}$ 


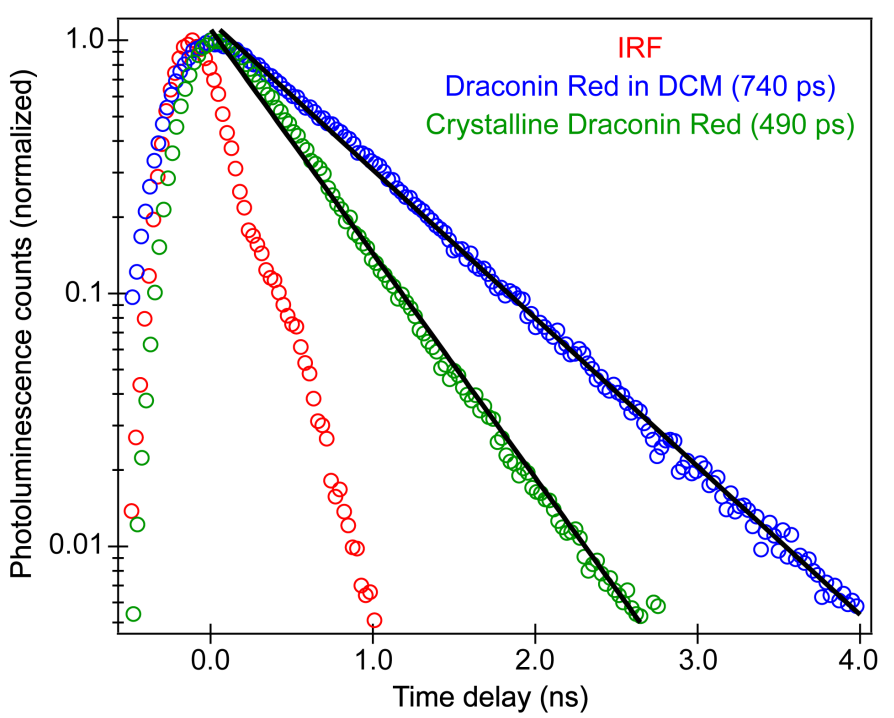

Figure S8. Excited-state lifetime measurements via time-correlated single photon counting (TCSPC) after $532 \mathrm{~nm}$ excitation of Draconin Red in DCM (blue) and crystalline Draconin Red (green). The instrument response function (IRF, red) was measured to be 250 ps. The singleexponential fits without deconvolution in solution (740 ps) and crystalline (490 ps) phases are shown as solid lines (black) overlaid with the normalized data points (color-coded open circles).

Notably in the photoluminescence (PL) lifetime experiments, a pulsed (500 kHz repetition rate, $\sim 45$ ps pulse duration) frequency-doubled Nd:YAG laser at $532 \mathrm{~nm}$ (NE Fianium 1060) was used for excitation, and TCSPC data were collected using an avalanche photodiode (Molecular Photonic Devices, Inc.) and a TimeHarp 200 card/NANO model (PicoQuant, Inc.). A full IRF deconvolution for Draconin Red data in DCM yields 690 ps. The decay time constants vary to some extent from crystal to crystal, and the one above (green circles) shows the least amount of delayed fluorescence (which could be caused by self-absorption and re-emission). The retrieved $490 \mathrm{ps}$ is shorter than the decay in solution, typical of materials used in organic electronics (same trend was observed in xylindein and dimethylxylindein solutions vs. thin films $)^{9,14}-$ we attributed this to intermolecular interactions opening up nonradiative relaxation channels not accessible to isolated molecules. ${ }^{15}$ 


\section{$\underline{\text { SI References }}$}

(1) Liu, W.; Han, F.; Smith, C.; Fang, C. Ultrafast Conformational Dynamics of Pyranine during Excited State Proton Transfer in Aqueous Solution Revealed by Femtosecond Stimulated Raman Spectroscopy. J. Phys. Chem. B 2012, 116, 10535-10550.

(2) Wang, Y.; Liu, W.; Tang, L.; Oscar, B. G.; Han, F.; Fang, C. Early Time Excited-State Structural Evolution of Pyranine in Methanol Revealed by Femtosecond Stimulated Raman Spectroscopy. J. Phys. Chem. A 2013, 117, 6024-6042.

(3) Chen, C.; Zhu, L.; Baranov, M. S.; Tang, L.; Baleeva, N. S.; Smirnov, A. Y.; Yampolsky, I. V.; Solntsev, K. M.; Fang, C. Photoinduced Proton Transfer of GFP-Inspired Fluorescent Superphotoacids: Principles and Design. J. Phys. Chem. B 2019, 123, 3804-3821.

(4) Fang, C.; Tang, L.; Chen, C. Unveiling Coupled Electronic and Vibrational Motions of Chromophores in Condensed Phases. J. Chem. Phys. 2019, 151, 200901.

(5) Vega Gutierrez, S. M.; Hazell, K. K.; Simonsen, J.; Robinson, S. C. Description of a Naphthoquinonic Crystal Produced by the Fungus Scytalidium cuboideum. Molecules 2018, 23, 1905.

(6) Piatkowski, L.; Accanto, N.; van Hulst, N. F. Ultrafast Meets Ultrasmall: Controlling Nanoantennas and Molecules. ACS Photonics 2016, 3, 1401-1414.

(7) Scholes, G. D.; Fleming, G. R.; Chen, L. X.; Aspuru-Guzik, A.; Buchleitner, A.; Coker, D. F.; Engel, G. S.; van Grondelle, R.; Ishizaki, A.; Jonas, D. M.; et al. Using Coherence to Enhance Function in Chemical and Biophysical Systems. Nature 2017, 543, 647-656.

(8) Krueger, T. D.; Boulanger, S. A.; Zhu, L.; Tang, L.; Fang, C. Discovering a Rotational Barrier within a Charge-Transfer State of a Photoexcited Chromophore in Solution. Struct. Dyn. 2020, 7, 024901. 
(9) Giesbers, G.; Krueger, T. D.; Van Schenck, J. D. B.; Kim, R.; Van Court, R. C.; Robinson, S. C.; Beaudry, C. M.; Fang, C.; Ostroverkhova, O. Role of Hydroxyl Groups in the Photophysics, Photostability, and (Opto)electronic Properties of the Fungi-Derived Pigment Xylindein. J. Phys. Chem. C 2021, 125, 6534-6545.

(10) Krueger, T. D.; Giesbers, G.; Van Court, R. C.; Zhu, L.; Kim, R.; Beaudry, C. M.; Robinson, S. C.; Ostroverkhova, O.; Fang, C. Ultrafast Dynamics and Photoresponse of a FungiDerived Pigment Xylindein from Solution to Thin Films. Chem. Eur. J. 2021, 27, 5627-5631.

(11) Berera, R.; van Grondelle, R.; Kennis, J. M. Ultrafast Transient Absorption Spectroscopy: Principles and Application to Photosynthetic Systems. Photosynth. Res. 2009, 101, 105-118.

(12) Kim, P. W.; Rockwell, N. C.; Martin, S. S.; Lagarias, J. C.; Larsen, D. S. Dynamic Inhomogeneity in the Photodynamics of Cyanobacterial Phytochrome Cph1. Biochemistry 2014, $53,2818-2826$.

(13) Tang, L.; Liu, W.; Wang, Y.; Zhu, L.; Han, F.; Fang, C. Ultrafast Structural Evolution and Chromophore Inhomogeneity inside a Green-Fluorescent-Protein-Based $\mathrm{Ca}^{2+}$ Biosensor. J. Phys. Chem. Lett. 2016, 7, 1225-1230.

(14) Giesbers, G.; Van Schenck, J.; Quinn, A.; Van Court, R.; Vega Gutierrez, S. M.; Robinson, S. C.; Ostroverkhova, O. Xylindein: Naturally Produced Fungal Compound for Sustainable (Opto)electronics. ACS Omega 2019, 4, 13309-13318.

(15) Ostroverkhova, O. Organic Optoelectronic Materials: Mechanisms and Applications. Chem. Rev. 2016, 116, 13279-13412. 


\section{Full Authorship for the Gaussian 09 Software:}

Frisch, M. J.; Trucks, G. W.; Schlegel, H. B.; Scuseria, G. E.; Robb, M. A.; Cheeseman, J. R.; Scalmani, G.; Barone, V.; Mennucci, B.; Petersson, G. A.; Nakatsuji, H.; Caricato, M.; Li, X.; Hratchian, H. P.; Izmaylov, A. F.; Bloino, J.; Zheng, G.; Sonnenberg, J. L.; Hada, M.; Ehara, M.; Toyota, K.; Fukuda, R.; Hasegawa, J.; Ishida, M.; Nakajima, T.; Honda, Y.; Kitao, O.; Nakai, H.; Vreven, T.; J. A. Montgomery, J.; Peralta, J. E.; Ogliaro, F.; Bearpark, M.; Heyd, J. J.; Brothers, E.; Kudin, K. N.; Staroverov, V. N.; Kobayashi, R.; Normand, J.; Raghavachari, K.; Rendell, A.; Burant, J. C.; Iyengar, S. S.; Tomasi, J.; Cossi, M.; Rega, N.; Millam, J. M.; Klene, M.; Knox, J. E.; Cross, J. B.; Bakken, V.; Adamo, C.; Jaramillo, J.; Gomperts, R.; Stratmann, R. E.; Yazyev, O.; Austin, A. J.; Cammi, R.; Pomelli, C.; Ochterski, J. W.; Martin, R. L.; Morokuma, K.; Zakrzewski, V. G.; Voth, G. A.; Salvador, P.; Dannenberg, J. J.; Dapprich, S.; Daniels, A. D.; Farkas, Ö.; Foresman, J. B.; Ortiz, J. V.; Cioslowski, J.; Fox, D. J.

\section{Full Authorship for the Gaussian 16 Software:}

Frisch, M. J.; Trucks, G. W.; Schlegel, H. B.; Scuseria, G. E.; Robb, M. A.; Cheeseman, J. R.; Scalmani, G.; Barone, V.; Petersson, G. A.; Nakatsuji, H.; Li, X.; Caricato, M.; Marenich, A. V.; Bloino, J.; Janesko, B. G.; Gomperts, R.; Mennucci, B.; Hratchian, H. P.; Ortiz, J. V.; Izmaylov, A. F.; Sonnenberg, J. L.; Williams; Ding, F.; Lipparini, F.; Egidi, F.; Goings, J.; Peng, B.; Petrone, A.; Henderson, T.; Ranasinghe, D.; Zakrzewski, V. G.; Gao, J.; Rega, N.; Zheng, G.; Liang, W.; Hada, M.; Ehara, M.; Toyota, K.; Fukuda, R.; Hasegawa, J.; Ishida, M.; Nakajima, T.; Honda, Y.; Kitao, O.; Nakai, H.; Vreven, T.; Throssell, K.; Montgomery Jr., J. A.; Peralta, J. E.; Ogliaro, F.; Bearpark, M. J.; Heyd, J. J.; Brothers, E. N.; Kudin, K. N.; Staroverov, V. N.; Keith, T. A.; Kobayashi, R.; Normand, J.; Raghavachari, K.; Rendell, A. P.; Burant, J. C.; Iyengar, S. S.; 
Tomasi, J.; Cossi, M.; Millam, J. M.; Klene, M.; Adamo, C.; Cammi, R.; Ochterski, J. W.; Martin, R. L.; Morokuma, K.; Farkas, O.; Foresman, J. B.; Fox, D. J. 
Appendix: Optimized Structures of Two Tautomers (PA and PS) of Draconin Red in $\mathbf{S}_{0}$

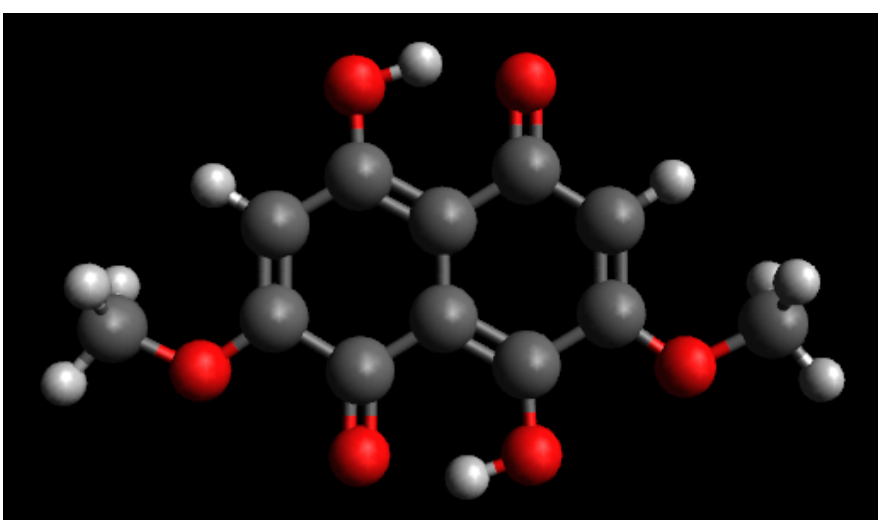

\begin{tabular}{|c|c|c|c|c|}
\hline \multicolumn{5}{|c|}{ PA } \\
\hline \multirow{2}{*}{ Atom Number } & \multirow{2}{*}{ Atom } & \multicolumn{3}{|c|}{ Cartesian Coordinates (Angstroms) } \\
\hline & & $\mathrm{X}$ & $\mathrm{Y}$ & $\mathrm{Z}$ \\
\hline 1 & $\mathrm{C}$ & 1.233776 & 1.729383 & -0.000017 \\
\hline 2 & $\mathrm{C}$ & 2.46848 & 0.978295 & 0.00012 \\
\hline 3 & $\mathrm{C}$ & 2.47754 & -0.38928 & 0.00007 \\
\hline 4 & $\mathrm{C}$ & 1.223089 & -1.13354 & 0.000175 \\
\hline 5 & $\mathrm{C}$ & 0.010705 & -0.44612 & 0.000153 \\
\hline 6 & $\mathrm{C}$ & -0.00062 & 0.983566 & 0.000099 \\
\hline 7 & $\mathrm{C}$ & -1.22683 & 1.651232 & 0.000025 \\
\hline 8 & $\mathrm{C}$ & -2.46641 & 0.937863 & -0.00014 \\
\hline 9 & $\mathrm{C}$ & -2.4866 & -0.42832 & -0.00017 \\
\hline 10 & $\mathrm{C}$ & -1.22192 & -1.20685 & 0.000156 \\
\hline 11 & $\mathrm{O}$ & 1.23513 & 2.997205 & 0.000055 \\
\hline 12 & $\mathrm{O}$ & -1.28417 & 2.976017 & 0.000132 \\
\hline 13 & $\mathrm{O}$ & 1.294311 & -2.45238 & 0.000254 \\
\hline 14 & $\mathrm{O}$ & -1.23755 & -2.45746 & 0.000313 \\
\hline 15 & $\mathrm{H}$ & -0.31899 & 3.288289 & 0.000337 \\
\hline 16 & $\mathrm{H}$ & 0.344748 & -2.78036 & 0.000255 \\
\hline 17 & $\mathrm{O}$ & 3.564604 & -1.1708 & -0.000056 \\
\hline 18 & $\mathrm{O}$ & -3.57679 & -1.19619 & -0.00043 \\
\hline 19 & $\mathrm{C}$ & -4.86687 & -0.56505 & -0.00011 \\
\hline 20 & $\mathrm{C}$ & 4.858818 & -0.54894 & -0.00047 \\
\hline 21 & $\mathrm{H}$ & 5.57364 & -1.36763 & -0.00101 \\
\hline 22 & $\mathrm{H}$ & 4.990646 & 0.062424 & -0.89626 \\
\hline 23 & $\mathrm{H}$ & 4.991408 & 0.062191 & 0.895386 \\
\hline 24 & $\mathrm{H}$ & -4.99359 & 0.047326 & 0.89583 \\
\hline 25 & $\mathrm{H}$ & -4.99416 & 0.046858 & -0.89628 \\
\hline 26 & $\mathrm{H}$ & -5.5882 & -1.3779 & 0.000187 \\
\hline 27 & $\mathrm{H}$ & -3.37495 & 1.52434 & -0.00013 \\
\hline 28 & $\mathrm{H}$ & 3.38614 & 1.5499 & 0.000279 \\
\hline
\end{tabular}




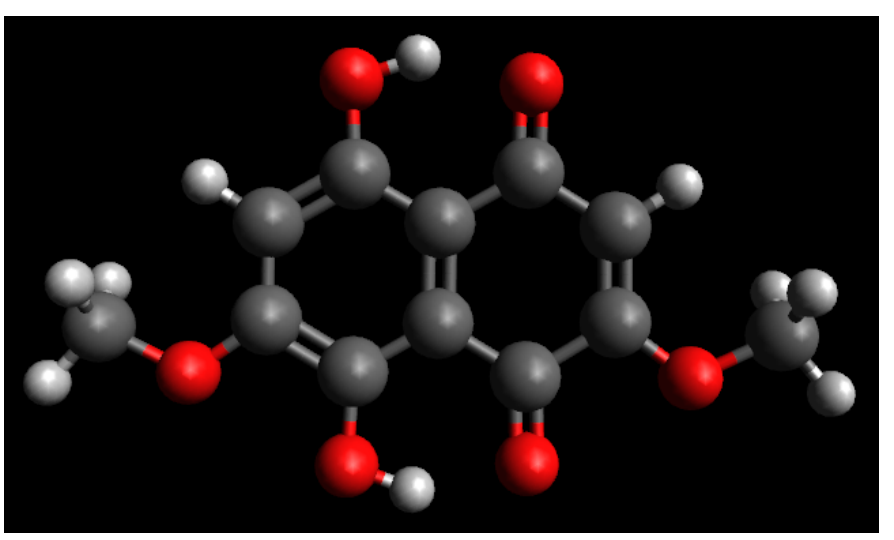

\begin{tabular}{|c|c|c|c|c|}
\hline \multicolumn{5}{|c|}{ PS } \\
\hline \multirow{2}{*}{ Atom Number } & \multirow{2}{*}{ Atom } & \multicolumn{3}{|c|}{ Cartesian Coordinates (Angstroms) } \\
\hline & & $\mathrm{X}$ & $\mathrm{Y}$ & $\mathrm{Z}$ \\
\hline 1 & $\mathrm{C}$ & 1.230381 & 1.667571 & 0.00005 \\
\hline 2 & $\mathrm{C}$ & 2.450721 & 0.957664 & 0.000138 \\
\hline 3 & $\mathrm{C}$ & 2.463373 & -0.42191 & 0.000163 \\
\hline 4 & $\mathrm{C}$ & 1.224786 & -1.14932 & 0.000113 \\
\hline 5 & $\mathrm{C}$ & 0.017586 & -0.4439 & 0.000018 \\
\hline 6 & $\mathrm{C}$ & 0.010323 & 0.982083 & -0.000021 \\
\hline 7 & $\mathrm{C}$ & -1.24771 & 1.710719 & -0.000071 \\
\hline 8 & $\mathrm{C}$ & -2.49222 & 0.956643 & -0.000063 \\
\hline 9 & $\mathrm{C}$ & -2.50813 & -0.40017 & -0.00018 \\
\hline 10 & $\mathrm{C}$ & -1.23537 & -1.18868 & -0.00015 \\
\hline 11 & $\mathrm{O}$ & 1.293871 & 3.006876 & 0.000091 \\
\hline 12 & $\mathrm{O}$ & -1.27328 & 2.964745 & -0.00013 \\
\hline 13 & $\mathrm{O}$ & 1.295006 & -2.48258 & 0.000189 \\
\hline 14 & $\mathrm{O}$ & -1.27395 & -2.42742 & -0.00018 \\
\hline 15 & $\mathrm{H}$ & 0.361585 & -2.81476 & 0.00016 \\
\hline 16 & $\mathrm{O}$ & 3.56535 & -1.18858 & 0.00026 \\
\hline 17 & $\mathrm{O}$ & -3.58902 & -1.17963 & -0.00038 \\
\hline 18 & $\mathrm{C}$ & -4.88457 & -0.55858 & 0.000407 \\
\hline 19 & $\mathrm{C}$ & 4.850041 & -0.55019 & -0.00031 \\
\hline 20 & $\mathrm{H}$ & 5.575855 & -1.35941 & -0.00098 \\
\hline 21 & $\mathrm{H}$ & 4.977094 & 0.06257 & -0.89618 \\
\hline 22 & $\mathrm{H}$ & 4.978139 & 0.062121 & 0.895701 \\
\hline 23 & $\mathrm{H}$ & -5.01485 & 0.052744 & 0.896392 \\
\hline 24 & $\mathrm{H}$ & -5.01573 & 0.053023 & -0.89529 \\
\hline 25 & $\mathrm{H}$ & -5.59922 & -1.37726 & 0.000612 \\
\hline 26 & $\mathrm{H}$ & -3.40122 & 1.542783 & 0.000031 \\
\hline 27 & $\mathrm{H}$ & 3.367204 & 1.530768 & 0.00022 \\
\hline 28 & $\mathrm{H}$ & 0.35197 & 3.328459 & 0.000035 \\
\hline
\end{tabular}

